\title{
Seasonal Variation of Group a Streptococcus (GAS) - Related Necrotising Fasciitis Cases in a UK Teaching Hospital
}

\author{
E. Gkrania-Klotsas*,1, R.C. Chew ${ }^{2}$ and K. Vrotsou ${ }^{3}$ \\ ${ }^{1}$ Box 25/Ward D10, Addenbrooke's Hospital, Cambridge, CB2 2QQ, UK \\ ${ }^{2}$ University of Cambridge Medical School, Peterhouse, Cambridge, CB2 1RD, UK \\ ${ }^{3}$ Centre for Applied Medical Statistics, Department of Public Health and Primary Care, University of Cambridge, For- \\ vie Site, Institute of Public Health, Robinson Way, Cambridge CB2 2SR, UK
}

\begin{abstract}
Objectives: Necrotizing fasciitis is a diverse syndrome primarily involving the fascia but also occasionally the overlying skin and underlying muscles. Non-necrotising lower limb cellulitis has been reported to have a marked seasonal variation in our area. We are describing the seasonal variation of our necrotising fasciitis cases.

Methods: The medical records of all the patients that were admitted to our institution with a diagnosis of necrotizing fasciitis, from January 1994 to December 2003, were retrospectively reviewed.

Results: The necrotising fasciitis infections peaked every year in the spring time, as previously described for cellulitis. The increased incidence was only apparent for group A streptococcus related necrotising fasciitis cases. The diagnosis carried $21 \%$ mortality during the same admission. Overall, $39 \%$ of the patients had a bad outcome, defined as either death during the same admission, limb amputation or severe disability. $73 \%$ of patients who experienced a bad outcome were found to have Group A streptococcus compared to only $41 \%$ of the patients in the good outcome group.

Conclusions: A seasonal variation was noted for Group A streptococcus associated necrotising fasciitis, that remains a lethal condition. As patients with Group A streptococcus associated necrotising fasciitis tend to have a worse outcome in our series, increased awareness and targeted antibiotic therapy may enhance clinical outcomes. Knowledge of microbiology might also inform infection control decisions.
\end{abstract}

Keywords: Necrotising fasciitis, Group A Streptococcus, Epidemiology.

\section{INTRODUCTION}

Necrotizing fasciitis is characterized by widespread fascial necrosis with relative sparing of skin and muscle. Despite the availability of very active, broad-spectrum antibiotics, the morbidity and mortality rates of necrotizing fasciitis have not substantially changed over time [1].

The exact epidemiology of necrotising fasciitis is unknown, mostly because of confusion in the literature as to the precise definition and the use of multiple terms including but not limited to suppurative fasciitis, acute dermal gangrene, Fournier's gangrene (necrotising fasciitis of the male genitalia), haemolytic streptococcal gangrene, necrotizing erysipelas, progressive synergistic bacterial gangrene. There is no age or sex predilection and it can happen in both healthy and previously immunosuppressed individuals [2].

Necrotising fasciitis is commonly classified into two major types. Type 1 is polymicrobial in origin. Examples of this type would include Fournier's gangrene and postoperative infections. Type 2 is commonly monomicrobial, usually caused by Group A streptococcus $(\boldsymbol{G A S})$ alone or with coagulase-negative staphylococcus [3]. Although this classification exists there is infrequently adequate data available to differentiate these types in the clinical scenario and for

*Address correspondence to this author at the Box 25/Ward D10, Addenbrooke's Hospital, Cambridge, CB2 2QQ, UK; Tel: +44-1223-216243; Fax: +44-1223-256252; E-mail: egkraniaklotsas@nhs.net practical purposes cases are treated identically. Surgical debridement is the mainstay of therapy, supplemented with parenteral antibiotics and supportive care including nutritional care.

In our institution, admissions for non-necrotising lower limb cellulitis have been shown to increase markedly during the months of April to July [4]. We were interested in describing any seasonality of necrotising fasciitis infections and the associated microbiology. Knowledge of this information may help inform the decision of antibiotic choice, especially with the recent emergence of GAS Clindamycin resistance [5]. Also, because of the need to isolate a patient with a possible group A streptococcus infection in order to prevent transmission, knowledge of the exact microbiology might inform infection control decisions.

\section{PATIENTS AND METHODS}

The medical records of all patients who had been treated in our institution for necrotizing fasciitis over a ten year period between January 1994 and December 2003 were retrospectively reviewed. Patients who had been diagnosed with necrotising fasciitis (International Classification of Diseases, Ninth Revision) were identified through the Medical Audit Department and 32 consecutive records were found, however three of them were unavailable for analysis. The list was further cross-checked with a list maintained by the infectious diseases department. It was verified that all patients included in the study had demonstrable lack of resistance of normally 
adherent fascia to blunt dissection during surgery documented into their record. The lack of the above criterion led us to exclude one more patient from the analysis. A total of 28 patients were used for this study.

The variables examined in this study included age, gender, location of infection, type of symptoms, laboratory findings at the time of admission, time from admission to surgery, microbiological isolates from tissue and bodily fluid samples, the number of operative debridements, the need for amputation and the in-hospital mortality rate. The LRINEC (Laboratory Risk Indicator for Necrotizing Fasciitis) score was calculated. The type, number and actual hours of antibiotic use and the use of NSAIDS before surgery were also analysed. The outcomes of the patients were also documented, with bad outcome defined as either death during the same admission, limb amputation or severe disability.

Statistical analysis was performed with the software SPSS 12.0.1. Continuous variables are presented with medians and ranges, and categorical ones with frequencies and percentages. Two-group comparisons were made with the Median test, whereas associations between variables were tested with Fisher's exact. The significance level was set at 0.05 .

\section{RESULTS}

31 patients with necrotising fasciitis were treated in our institution within the period under review.

The group included 13 men (42\%) and 18 women (58\%) with a mean (range) age of 58.7 years (24 to 99 ).

The following information pertains to the 28 patients from whom full data were available. Only data pertaining to the time of admission were used.

\section{Anatomical Area}

The infection involved the anatomical area of the periorbital region / face or neck in $3(10.7 \%)$ patients, the genitals or perirectal tissues in $4(14.3 \%)$ patients, the torso in 3 $(10.7 \%)$ patients and the limbs in $18(64.3 \%)$ patients (lower limbs in 15 out of 18 patients). The most common site of infection was one of the limbs, mostly the lower extremities.

\section{Comorbidities}

Comorbidities included diabetes in $6(21.4 \%)$ patients. Four $(14.3 \%)$ of the patients had a previous solid tumour diagnosis and $5(17.8 \%)$ had peripheral vascular disease. Other comorbidities in our patient group are presented in Table 3.

\section{Clinical Presentation}

The laboratory data and presenting symptoms at the time of admission are presented in Tables $\mathbf{1}$ and $\mathbf{2}$.

The majority of patients presented with the triad of exquisite pain, swelling and fever. An oral temperature exceeding $37.5^{\circ} \mathrm{C}$ was observed in $18(64.3 \%)$ and an oral temperature exceeding $38{ }^{\circ} \mathrm{C}$ in 11 (39.3\%) of the patients.

The Laboratory Risk Indicator for Necrotizing Fasciitis (LRINEC) score [6] at the time of admission was calculated for the 18 patients that had all the data available. The maximum score is 13. It is suggested that a score equal or more than 6 should raise the clinical suspicion for necrotizing fasciitis and a score equal or more than 8 is strongly predictive of the disease.

Table 1. Symptoms and Signs of Admission: Median (Range)

\begin{tabular}{|l|l|}
\hline Heart rate (beats/ minute) & $108(69$ to 142$)$ \\
\hline Diastolic blood pressure (mmHg) & $60(30$ to 92$)$ \\
\hline Systolic blood pressure (mmHg) & $111(70$ to 186$)$ \\
\hline Air oxygen saturation & $96 \%(88$ to $100 \%)$ \\
\hline Oral temperature $>38.5^{\circ} \mathrm{C}, \mathrm{n}(\%)$ & $8(29)$ \\
\hline Confusion present, $\mathrm{n}(\%)$ & $4(14)$ \\
\hline Severe Pain, $\mathrm{n}(\%)$ & $26(92.8 \%)$ \\
\hline Skin anaesthesia, $\mathrm{n}(\%)$ & $1(3.6 \%)$ \\
\hline Crepitus, $\mathrm{n}(\%)$ & $7(25 \%)$ \\
\hline Oedema, $\mathrm{n}(\%)$ & $23(82 \%)$ \\
\hline Change of Skin Colour, $\mathrm{n}(\%)$ & $6(21.4 \%)$ \\
\hline
\end{tabular}

Table 2. Laboratory Data on Admission: Median (Range)

\begin{tabular}{|l|l|}
\hline Total white blood cell count in thousands & $19.20(0.8$ to 60.6$)$ \\
\hline Haemoglobin $(\mathrm{g} / \mathrm{dl})$ & $11.9(8.1$ to 16.6$)$ \\
\hline Glucose $(\mathrm{mmol} / \mathrm{l})$ & $6.41(3.7$ to 13.3$)$ \\
\hline Creatinine $(\mu \mathrm{mol} / \mathrm{l})$ & $212.7(41$ to 861$)$ \\
\hline Albumin (in $\mathrm{g} / \mathrm{l})$ & $21(5$ to 35$)$ \\
\hline $\begin{array}{l}\text { LRINEC score (where all data available) } \\
\text { Score_6 } \\
\text { Score_8 }\end{array}$ & $\begin{array}{l}14 / 18 \\
9 / 18\end{array}$ \\
\hline
\end{tabular}

Table 3. Frequencies for Each Comorbidity Type Present at the Time of Admission

\begin{tabular}{|l|l|}
\hline Comorbidity type & $\boldsymbol{N}(\%)$ \\
\hline \hline Eczema & $1(3.6)$ \\
\hline Previous VZV of the area & $1(3.6)$ \\
\hline Psoriasis & $1(3.6)$ \\
\hline Connective tissue disease & $1(3.6)$ \\
\hline Morbid obesity & $1(3.6)$ \\
\hline Liver disease & $3(10.7)$ \\
\hline Coronary Artery Disease & $3(10.7)$ \\
\hline Congestive Heart Failure & $3(10.7)$ \\
\hline Cancer & $4(14.3)$ \\
\hline Cerebrovascular Disease & $4(14.3)$ \\
\hline Hypertension & $4(14.3)$ \\
\hline Peripheral Vascular Disease & $5(17.8)$ \\
\hline Diabetes mellitus & $6(21.4)$ \\
\hline Renal disease predating this admission & $7(25)$ \\
\hline
\end{tabular}


Table 4. Samples with Positive Cultures, Micro Organisms Identified and Presence of Concurrent Bacteraemia for all 28 Patients

\begin{tabular}{|c|c|c|c|}
\hline Patient & $\begin{array}{l}\text { Samples that had positive } \\
\text { cultures }\end{array}$ & Microorganisms identified from cultures & $\begin{array}{c}\text { Concurrent bacteraemia } \\
\text { present }\end{array}$ \\
\hline 1 & $\begin{array}{c}\text { Blood culture } \\
\text { Operative fluid swab }\end{array}$ & $\begin{array}{c}\text { Coagulase negative staphylococci from blood and } \\
\text { Group A Streptococcus from fluid }\end{array}$ & Yes \\
\hline $2,3,11,16$ & Operative fluid swab & Group A Streptococcus & No \\
\hline 4 & Operative fluid swab & Group A Streptococcus, Staphylococcus aureus and diphtheroids & No \\
\hline 5 & Operative fluid swab & Staphylococcus aureus and coagulase negative staphylococci & No \\
\hline 6 & Blood culture & Group A Streptococcus & Yes \\
\hline 7 & Operative fluid swab & Proteus mirabilis, Gram positive cocci, Gram positive bacilli & No \\
\hline 8 & Operative fluid swab & Escherichia coli & No \\
\hline 9 & Blood culture & Group A Streptococcus & Yes \\
\hline 10 & Tissue culture & Group A Streptococcus & $\begin{array}{l}\text { No blood culture } \\
\text { available }\end{array}$ \\
\hline 12 & Perioperative death & Culture not sent & No \\
\hline 13 & Blood culture & Clostridium perfringens & Yes \\
\hline 14 & Tissue culture & $\begin{array}{l}\text { Citrobacter koseri, anaerobes, Gram positive cocci, Gram positive bacilli, } \\
\text { Gram negative bacilli }\end{array}$ & No \\
\hline 15 & Tissue culture & Proteus mirabilis and multiple other organisms & No \\
\hline 17 & Operative fluid swab & Group A Streptococcus & Not sent \\
\hline 18 & $\begin{array}{l}\text { Blood culture } \\
\text { Operative fluid swab }\end{array}$ & $\begin{array}{l}\text { Group A Streptococcus from blood culture, fluid } \\
\text { Enterobacter cloacae from operative fluid only }\end{array}$ & Yes \\
\hline 19 & $\begin{array}{l}\text { Tissue culture } \\
\text { Blood culture Operative fluid } \\
\text { swab }\end{array}$ & Group A Streptococcus from all specimens & Yes \\
\hline 20 & $\begin{array}{l}\text { Tissue culture } \\
\text { Operative fluid swab }\end{array}$ & Gram positive cocci in chains, Gram positive bacilli, anaerobes & No \\
\hline 21 & $\begin{array}{l}\text { Tissue culture } \\
\text { Operative fluid swab }\end{array}$ & Staphylococcus aureus from operative fluid swab only & No \\
\hline 22 & $\begin{array}{l}\text { Tissue culture } \\
\text { Blood culture Operative fluid } \\
\text { swab }\end{array}$ & no growth from any specimen & No \\
\hline 23 & $\begin{array}{l}\text { Tissue culture } \\
\text { Blood culture Operative fluid } \\
\text { swab }\end{array}$ & Group A Streptococcus & Yes \\
\hline 24 & $\begin{array}{l}\text { Tissue culture } \\
\text { Blood culture }\end{array}$ & $\begin{array}{c}\text { Clostridia, } \\
\text { Anaerobes, Klebsiella species, } \\
\text { Escherichia coli and diphtheroids from tissue culture only. } \\
\text { Coagulase negative staphylococci from blood culture }\end{array}$ & Yes \\
\hline 25 & Operative fluid swab & Mixed gram negatives, predominance of coliform bacilli & No \\
\hline 26 & Operative fluid swab & Coagulase negative staphylococci & No \\
\hline 27 & $\begin{array}{l}\text { Tissue culture } \\
\text { Operative fluid swab }\end{array}$ & $\begin{array}{l}\text { Proteus mirabilis, } \\
\text { Fungi, } \\
\text { Acid-fast bacilli }\end{array}$ & No \\
\hline 28 & $\begin{array}{l}\text { Tissue culture } \\
\text { Blood culture Operative fluid } \\
\text { swab }\end{array}$ & Group A Streptococcus & Yes \\
\hline
\end{tabular}




\section{Involvement of the Fascia Planes}

During operation involvement of the fascia planes alone was documented in 14/24 patients (58\%); documentation about muscle involvement was missing for 4 patients. The remainder of the patients had concurrent myositis $(6 / 24)$.

\section{Microbiological Data}

Cultures of specimens received during the time of operation included tissue samples and swabs from operative fluid.

One of the twenty-eight patients did not receive an intraoperative culture due to a perioperative death. In one of the patients there was no growth. GAS was cultured from 14 $(50 \%)$ of the patients. Gram positive cocci in chains that did not grow in culture were visualized in the fluid specimen from one more patient.

A single organism was identified in $15(53.6 \%)$ patients. Multiple organisms (polymicrobial infection) were identified in $12(42.8 \%)$ patients. A concurrent bacteraemia was present in $9 / 27$ patients (33\%) but in two cases only coagulase negative staphylococci grew from the blood cultures. In three cases the blood culture was the only specimen positive, two with GAS and one with Clostridium perfringens.

The number of $G A S$-related necrotizing fasciitis cases appeared to increase over time (Fig. 2). GAS -related necrotizing fasciitis cases appeared to increase during the Spring and early Summer months (Fig. 3).

The microbiological diagnoses from the patients are presented in Table 4.

\section{Time from Admission to Surgery}

The exact times of admission and surgical procedure initiation were available for 21 of the 28 patients. The median (range) time from admission to surgery was 3.75 (0.5 to 228.7) hours for the first debridement episode. Most patients were operated within 24 hours, and 3 had to wait more than 1 day.

\section{Outcome Analysis}

The overall mortality during the same admission was $21 \%$ (6 patients).

A total of $11(39 \%)$ of patients suffered a bad outcome, defined as severe disability, amputation or death as a result of the necrotizing fasciitis. Amputation to control the infection was performed in $3(10.7 \%)$ of the patients, two of whom died because of the illness. A further more $4(14.3 \%)$ patients were left with other severe disability because of extensive tissue debridements. The rest survived with no amputation or other severe disability.

$73 \%$ of patients who experienced a bad outcome were found to have GAS infection compared to only $41 \%$ of the patients in the good outcome group $(32 \%, 95 \% \mathrm{CI}:-3.6$ to $67 \%$ ). There was a trend towards significance between the presence of $G A S$ and bad outcome ( $\mathrm{p}=0.102$, chi-square) although not with death $(\mathrm{p}=0.655)$. The use of Clindamycin before the surgery or during the same hospitalization was not associated with death or bad outcome.

The Kaplan-Meier curve indicated a non-statistically significant decrease in cumulative survival rate as the time between admission and the surgical operation increased (Fig. 1). More accurate estimations about survival probabilities can be found in previous studies [7,8].

\section{CONCLUSIONS- DISCUSSION}

We examined our clinical centre's experience with necrotizing fasciitis over a period of ten years.

Our results verify that necrotizing fasciitis continues to be a rare diagnosis with a high associated morbidity and mortality. The disease was diagnosed in almost all age groups. The pathogens isolated agree with commonly cited

$$
\text { Kaplan-Meier ourve }
$$

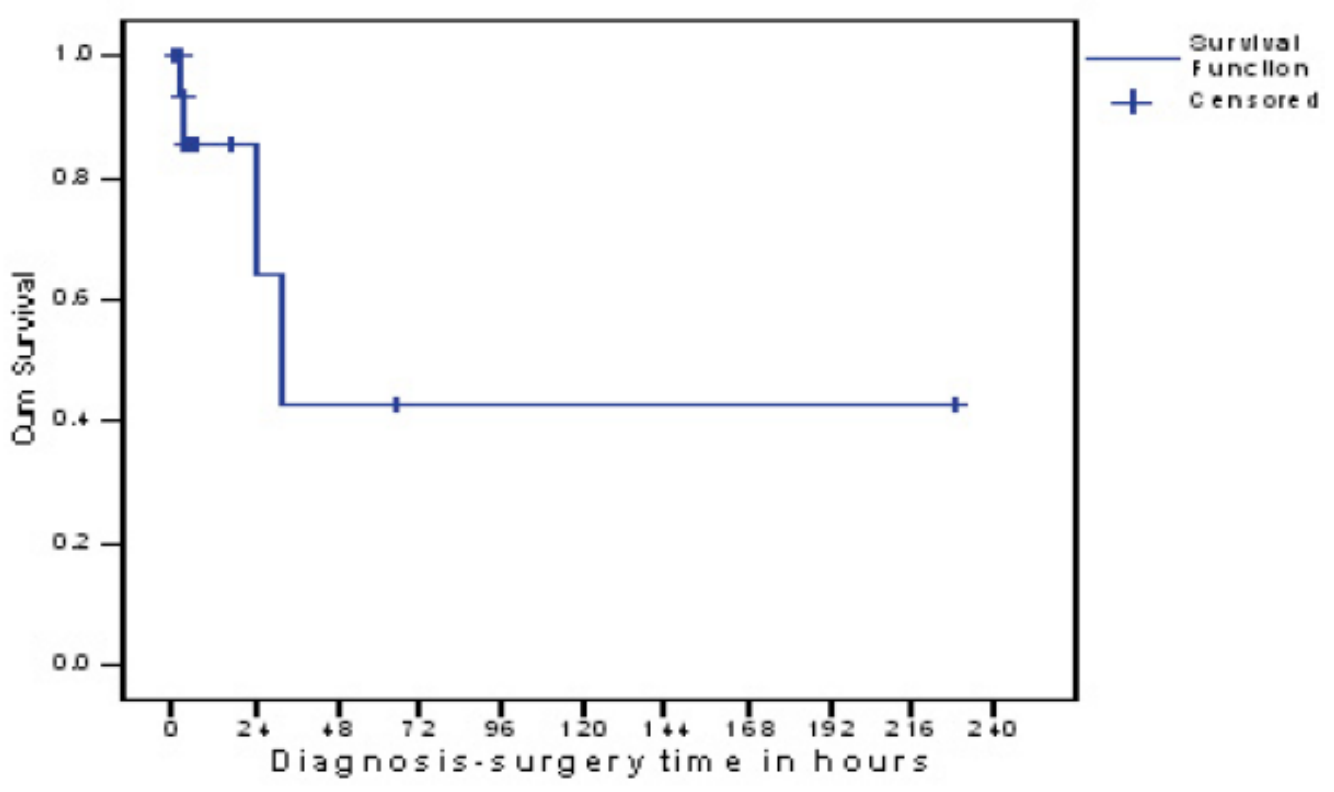

Fig. (1). 
surveys and the majority fell into the two groups of Group A streptococcus or polymicrobial infection.

In most of the patients the limbs were the major site of involvement.

One fifth of the patients had diabetes mellitus as an associated comorbidity. In our study renal failure was also common ( $25 \%$ of patients), but this observation might not be as accurate as the overall septic picture might have resulted in impaired renal function and therefore an erroneous diagnosis of underlying renal insufficiency. An association with renal failure has been identified in the past but the results were not stratified by diabetic status [9].

The presence of topical dermatological diseases (psoriasis, eczema and previous varicella-zoster infection of the same anatomical area) are intriguing as varicella zoster reactivation has been rarely reported to be associated with necrotising fasciitis $[10,11]$, while chickenpox is known to be associated especially with group A streptococci infection [12]. Unfortunately the patient specimens failed to grow (patient 22 on the list). This patient was not receiving NSAIDS prior to the development of necrotising fasciitis. The possibility of an erroneous diagnosis of zoster due to the presence of blisters could be entertained as well [13].

The simultaneous presence of psoriasis and necrotizing fasciitis that was recorded for one patient in our series has been described in a prior publication [14].

Five $(17.8 \%)$ of our patients had peripheral vascular disease before the occurrence of necrotising fasciitis- only one of them was a diabetic. The association of peripheral vascular disease with necrotizing fasciitis has been described before $[15,16]$.

Although comorbidity was identified in some patients, in approximately half the cases, the individual was previously well, emphasising the idiosyncratic occurrence of this life threatening condition in previously well adults. $87.5 \%$ of the previously healthy patients compared to $39 \%$ of the patients with comorbidities had Group A Streptococcus cultured from their clinical specimens.

The majority of patients presented with the triad of exquisite pain, swelling and fever.

Among 18 out of the 28 patients who had full data available, $77 \%$ of the patients had a LRINEC score equal or more than 6 at the time of admission, emphasizing the clinical utility of the LRINEC score to discriminate necrotising fasciitis from other soft tissue infections.

A polymicrobial infection was present in $43 \%$ of the patients. Only one organism was isolated in $54 \%$ of the patients. GAS was cultured from $14(50 \%)$ of the patients. More patients had gram positive cocci visualized in microscopy. Due to lack of available data, it was impossible to calculate exactly how many of the patients who had GAS cultured from their clinical specimens met the toxic shock syndrome definition.

The number of $G A S$-related necrotizing fasciitis cases appeared to increase over time (Fig. 2). Since the late 1980s several studies have described the increased incidence and severity of invasive $G A S$ infections. However, most studies on $G A S$ pathogenesis have focused on information obtained during outbreaks and population based studies have failed to show a similar picture [16-18]. The number of GAS bacteraemias reported by laboratories in England and Wales for the period 1993-2004 tripled from 568 to 1571 while the number of Group B streptococcus bacteraemias increased only by $30 \%$.The number of cases decreased, though, during 2005 [28]. In our series, most of the cases of GAS necrotising fasciitis happened during the 2000-2001 season, when a similar increasing incidence was noted among the injecting drug users in England and Wales [19]. Because of the large regional variation, it is difficult to speculate if this was a random event or if the two observations are associated.

Similarly, GAS-related necrotizing fasciitis cases appeared to increase during the Spring and early Summer months (Fig. 3). As described, this parallels our institution

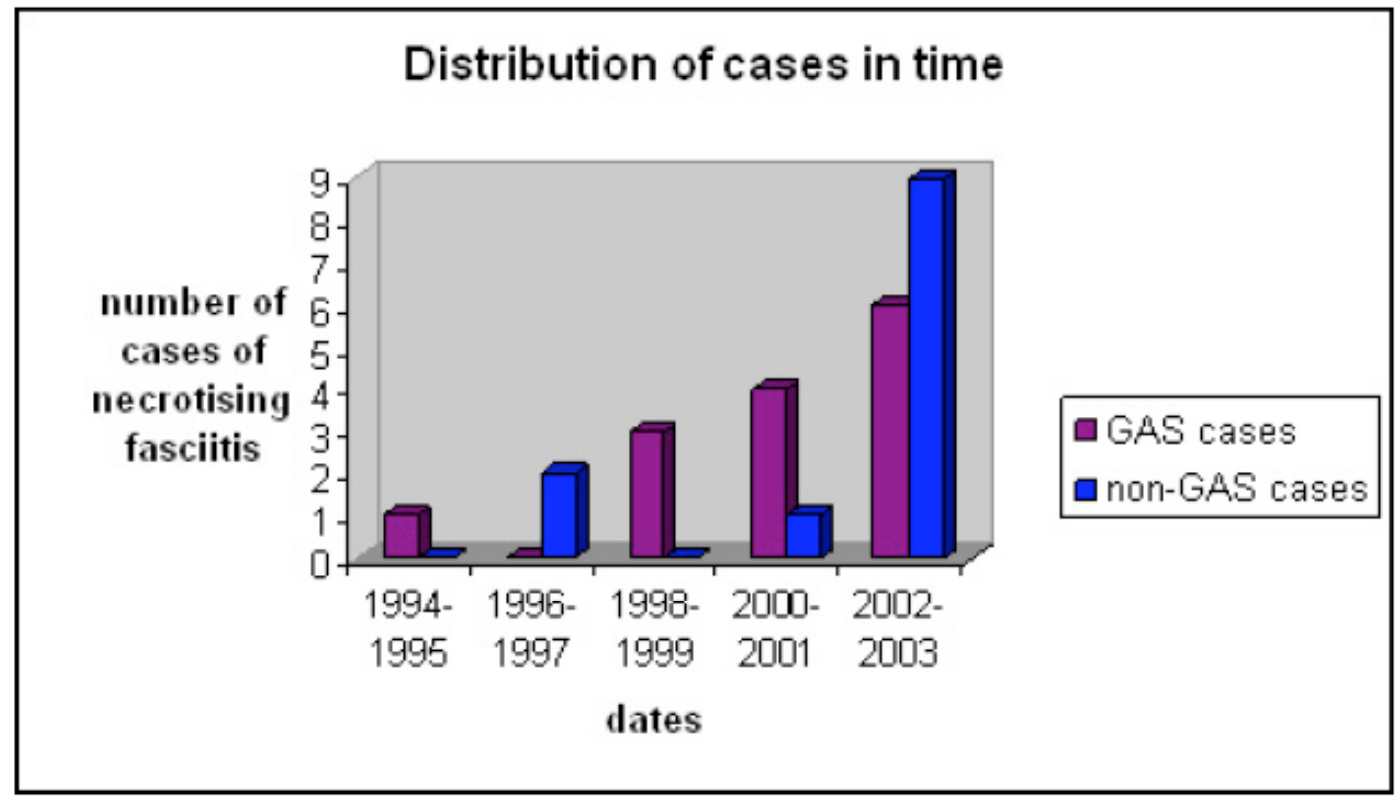

Fig. (2). 


\section{Seasonal variation}

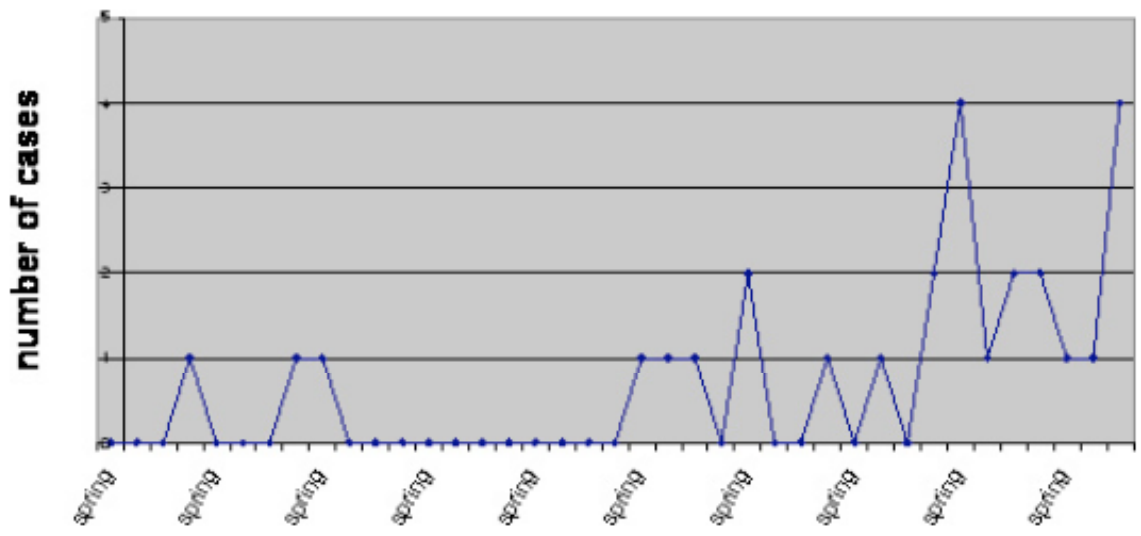

Fig. (3).

experience with microbiologically undifferentiated nonnecrotising lower limbs cellulitis [4]. Seasonal variations in streptococcal infections together with hypotheses about their aetiology have been described since 1966 [20, 21]. It is tempting to hypothesize that respiratory or mucosal carriage during the winter months as described in the past was related to subsequent development of necrotising fasciitis. Data from large surveillance databases, like the Strep-Euro project [22], might be able to answer this clinically relevant question.

Epidemiological studies analyzing the seasonal spread of specific streptococcal strains would be clinically useful.

Until the above epidemiological observation is confirmed in larger UK observational studies, we suggest that every patient brought to the attention of surgeons with a necrotising infection in the period of April to July is assumed to be infected with $G A S$ and infection control measures are instituted as dictated by local hospital policies to avoid transmission in the hospital. The local infectious diseases team or microbiology department should be consulted for prompt initiation of appropriate antibiotic treatment.

\section{NOTE}

Outcome results about this series were presented at the 44th Annual Meeting of the Infectious Diseases Society of America (IDSA), Abstract 583 on October 13, 2006 in Toronto, Canada.

\section{REFERENCES}

[1] Kaul, R.; McGeer, A.; Low, D.E.; Green, K.; Schwartz, B. Population-based surveillance for group A streptococcal necrotizing fasciitis: Clinical features, prognostic indicators, and microbiologic analysis of seventy-seven cases. Ontario Group A Streptococcal Study. Am. J. Med., 1997, 103(1)18-24.

[2] Green, R.J.; Dafoem D,C.; Raffin, T.A. Necrotizing fasciitis. Chest., 1996, 110(1), 219-229.

[3] Bisno, A.L.; Stevens, D.L. Streptococcal infections of skin and soft tissues. N. Engl. J. Med., 1996, 334(4), 240-245.

[4] Haydock, S.F.; Bronshin, s.; Wall, E.C.; Connick,S.M. Admission with non-necrotising lower limb cellulitis to a UK Teaching hospital show a marked seasonal variation. (Br. J. Dermatol., in Press).

[5] Walsh, S.R.; Ferraro, M.J.; Durand, M.L. Clindamycin-resistant Streptococcus pyogenes: report of a case. Diagn. Microbiol. Infect. Dis., 2004, 49(3):223-225.
[6] Wong, C.H.; Khin, L.W.; Heng, K.S.; Tan, K.C.; Low, C.O. The LRINEC (Laboratory Risk Indicator for Necrotizing Fasciitis) score: a tool for distinguishing necrotizing fasciitis from other soft tissue infections. Crit. Care Med., 2004, 32(7), 1535-1541.

[7] Wong, C.H.; Changm, H.C.; Pasupathy, S.; Khin, L.W.; Tan, J.L.; Low, C.O. Necrotizing fasciitis: clinical presentation, microbiology, and determinants of mortality. J Bone Joint Surg Am. 2003 Aug;85- (8):1454-60. Comment in: J. Bone Joint Surg. Am., 2004, 86- (4):869, author reply 869-70.

[8] McHenry, C.R.; Piotrowskim J.J.; Petrinicm, D.; Malangoni, M.A. Determinants of mortality for necrotizing soft-tissue infections. Ann. Surg., 1995, 221(5):558-563: discussion 563-5.

[9] Childers, B.J.; Potyondy, L.D.; Nachreiner, R.; Rogers, F.R.; Childersm E.R.; Oberg, K.C.; Hendricks, D.L.; Hardesty, R.A. Necrotizing fasciitis: a fourteen-year retrospective study of 163 consecutive patients. Am. Surg., 2002, 68(2):109-116.

[10] Sewell, G.S.; Hsu, V.P.; Jones, S.R. Zoster gangrenosum: necrotizing fasciitis as a complication of herpes zoster. Am. J. Med., 2000, 108(6):520-521.

[11] Jarrett, P.; Ha, T.; Oliver, F. Necrotizing fasciitis complicating disseminated cutaneous herpes zoster. Clin. Exp. Dermatol., 1998, 23(2):87-88.

[12] Tyrrell, G.J.; Lovgren, M.; Kress, B.; Grimsrud, K. Varicellaassociated invasive group A streptococcal disease in Alberta, Canada2000-2002. Clin. Infect. Dis., 2005, 40(7)1055-1057.

[13] Balaggan, K.S.; Goolamali, S.I. Periorbital necrotising fasciitis after minor trauma. Graefes Arch. Clin. Exp. Ophthalmol., 2006, 244(2):268-270.

[14] Chong, A.H.; Burrows, N.P. Fatal group A streptococcal necrotizing fasciitis and toxic shock syndrome in a patient with psoriasis and chronic renal impairment. Australas. J. Dermatol., 2002, 43(3):194-198.

[15] Elliott, D.C.; Kufera, J.A.; Myers, R.A. Necrotizing soft tissue infections. Risk factors for mortality and strategies for management. Ann. Surg., 1996, 224(5):672-683.

[16] Ekelund, K.; Darenberg, J.; Norrby-Teglund, A.; Hoffmann, S.; Bang, D.; SkinhГEj, P.; Konradsen, H.B. Variations in emm type among group A streptococcal isolates causing invasive or noninvasive infections in a nationwide study. J. Clin. Microbiol., 2005, 43(7):3101-3109.

[17] O'Brien, K.L.; Beall, B.; Barrett, N.L.; Cieslak, P.R.; Reingold, A.; Farley, M.M.; Danila, R.; Zell, E.R.; Facklam, R.; Schwartz, B.; Schuchat, A. Epidemiology of invasive group a streptococcus disease in the United States,1995-1999. Clin. Infect. Dis., 2002, 35(3):268-276

[18] Mencarelli, M.; Corbisiero, R.; Padula, M.G.; Galgani, I.; Stolzuoli, L.; Cellesi, C. Group A streptococcal infections: trend and strain emm typing in an area of central Italy, 1985-2002. Epidemiol. Infect., 2005, 133(6):1107-1111.

[19] Efstratiou, A.; Emery, M.; Lamagni, T.L.; Tanna, A.; Warner, M.; George, R.C. Increasing incidence of group A streptococcal infec- 
tions amongst injecting drug users in England and Wales. J. Med. Microbiol., 2003, 52(Pt 6):525-526.

[20] Boycott, J.A. Seasonal variations in streptococcal infections. Lancet., 1966, 1(7439):706-707.

[21] Morris, C.A.; Berry, D.M. Annual and seasonal variation in the frequency of beta-haemolytic streptococcal infections. J. Clin. Pathol., 1985, 38(5)594-595.
Jasir, A.; SchalГ@n, C. Strep-ERUO study group. Strep-EURO: progress in analysis and research into severe streptococcal disease in Europe, 2003-2004. Euro. Surveill., 2005, 310(2):E050203.3. 